\title{
The efficacy of negative pressure wound therapy on chemotherapeutic extravasation ulcers: An experimental study
}

\author{
Evren Iscı, Halil I. Canter ${ }^{1}$, Mehmet Dadacı ${ }^{2}$, Pergin Atılla ${ }^{3}$, Ayse N. Cakar ${ }^{3}$, Abdullah Kecık $^{4}$ \\ Departments of Plastic and Reconstructive Surgery, Private Aile Hospital, ${ }^{1}$ Faculty of Medicine, Acibadem University, Istanbul, \\ ${ }^{2}$ Faculty of Medicine, Necmettin Erbakan University Meram, Konya, ${ }^{3}$ Departments of Histology and Embryology and ${ }^{4}$ Plastic \\ and Reconstructive Surgery, Faculty of Medicine, Hacettepe University, Ankara, Turkey
}

Address for correspondence: Dr. Evren Isci, Department of Plastic and Reconstructive Surgery, Private Aile Hospital, Talatpasa Caddesi, Begonya Sokak No. 7, Bahcelievler, Istanbul, Turkey. E-mail: meddocevren@yahoo.com

\section{ABSTRACT}

Context: The extravasation of the chemotherapeutic agents is not an unusual phenomenon. Necrosis of the skin and underlying structures has been reported, depending on the cytotoxicity of the extravasating drug. Despite the presence of some antidotes, such wounds tend to enlarge with time and are likely to resist the treatment. Aims: The objective of this study was to investigate the efficacy of negative pressure wound therapy (NPWT) on extravasation ulcers. Settings and Design: Animals were separated into two groups; conventional dressing group and NPWT group. Materials and Methods: Extravasation necrosis was established by intradermal doxorubicin injection. Following the debridement of the necrotic areas, one group of animals was treated with the conventional dressing while NPWT was applied to the other group. The wound areas were measured, and then biopsies were taken on the $3^{\text {rd }}, 7^{\text {th }}$ and $14^{\text {th }}$ days after the debridement. Statistical Analysis Used: SPSS 11.5 for Windows was used. Two-way ANOVA test was used to compare wound areas between groups. Willcoxon sign test with Bonferroni correction was used to compare histological scores between groups. Chi-square test with Bonferroni correction was used to compare histological scores within the group between the days. Results: There is no significant difference in terms of inflammatory cell count, neovascularisation, granulation tissue formation between the groups. Contrary to these results wound areas at the end of the treatment were smaller in the NPWT group compared with the dressing group. Conclusion: There is the superiority of NPWT over conventional dressing in chemotherapeutic extravasation wounds as well as the wound area is concerned, but it is not proven histologically.

\section{KEY WORDS}

Chemotherapeutic extravasation; extravasation ulcer; negative pressure wound therapy; rabbit

\begin{tabular}{|l|l|}
\hline \multicolumn{2}{|c|}{ Access this article online } \\
\hline Quick Response Code: & Website: \\
\hline & www.ijps.org \\
\cline { 2 - 2 } & DOI: \\
\hline
\end{tabular}

\section{INTRODUCTION}

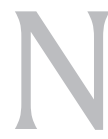

egative pressure wound therapy (NPWT) or vacuum-assisted closure $(\mathrm{VAC})^{\circledR}$ is based on the principal that negative pressure applied to the wound will promote an improved environment for wound healing. The concept of a vacuum was first presented by Evangelista Torriculli in the early $17^{\text {th }}$ century. In 1993 , 
Fleischmann described his technique of porous polyvinyl alcohol foam wrapped around suction drains, which was introduced into a wound sealed with a polyurethane drape and attached to a suction apparatus at $600 \mathrm{~mm} \mathrm{Hg}$. In 1997, Drs. Louis Argenta and Michael Morykwas presented their experience in NPWT at Wake Forest University in North Carolina with 175 chronic wounds, 94 subacute wounds, and 31 acute wounds over 9-year period. In a second paper published at the same time, they presented their animal study experience over the same 9-year period. ${ }^{[1]}$

Over the last 15 years, NPWT has become commonly used for treatment of a wide variety of complex wounds and has dramatically changed the way of treatment of such wounds. Many clinicians have noted a dramatic response when NPWT technology has been used for chronic open wounds, diabetic ulcers, stasis ulcers, acute and traumatic wounds, and dehisced wounds. ${ }^{[2]}$ Argenta et al. published a review on a wide variety of usage of NPWT devices on both acute and chronic wounds. ${ }^{[3]}$

Two broad mechanisms of action are proposed: Removal of fluid and mechanical deformation. Fluid removal both decreases edema - thus decreasing interstitial pressure and shortening distances of diffusion - and removes soluble factors such as inflammatory cytokines, collagenases and elastases that may affect the healing process ${ }^{[4]}$ Additionally, it improves the microcirculation, stimulates angiogenesis, provides a relative moist environment and reduces the bacterial count in the wound. Experimental evidence shows that up to fourfold increase in blood flow is achieved by the device set to $125 \mathrm{~mm} \mathrm{Hg}$ vacuum with 5 min on and 2 min off intervals. ${ }^{[5]}$ Chen et al. in an experimental study on rabbits found increase in blood flow increase in capillary calibre, increased endothelial proliferation and angiogenesis. ${ }^{[6]}$ Menke et al. discussed the possible mechanisms of chronic wound formation and mainly focused on the imbalance of inflammatory mediators and inhibitors of them especially matrix metalloproteinases (MMPs). ${ }^{[7]}$ Ladwig et al. assayed pro - and activated MMPs (MMP-2 and MMP-9), tissue inhibitors of metalloproteinases (TIMP-1 and TIMP-2), and the ratios of MMPs/TIMPs in fluids and biopsies collected from 56 patients with chronic pressure ulcers and showed that the ratio of MMP-9/TIMP-1 levels is a predictor of healing in pressure ulcers and high levels of MMP activity and low levels of MMP inhibitor impair wound healing in chronic pressure ulcers. NPWT also changes the microenvironment of the chronic wounds by suctioning out the chronic inflammatory mediators that are shown to be present in the chronic wound fluid and that decelarate the wound healing process. ${ }^{[8-10]}$ Greene et al. managed to prove that MMPs decrease in NPWT applied wounds. ${ }^{[1]]}$

The opinion as to whether fluid-based or mechanical properties have greater influence on clinical efficacy appears to be shifting towards mechanical properties. This is based on an article in which the authors showed that applied mechanical shear stresses were able to activate the vascular endothelial cell growth factor (VEGF) pathway without any VEGF being present in the culture fluid. ${ }^{[12]}$ Among factors activated in the VEGF pathway are extracellular regulated kinase and Jun $\mathrm{N}$-terminal protein kinase, which have been shown to be upregulated by stretch, not just shear stress. This line of research has been carried further into in vivo studies examining both acute wounds in swine and chronic wounds in humans. ${ }^{[13]}$ It is reported that an increase in several protooncogenes, including myc, c-Jun, and $\mathrm{Bcl}-2$, in both wound populations after VAC application. Thus, it appears that applied mechanical forces deform tissues, which results in deformation of cells; this is followed by stimulation of growth factor pathways, resulting in increased mitosis and production of new tissue.

The NPWT is contraindicated if homeostasis is not adequate. NPWT also is not indicated if necrotic or sloughing tissue is present in the wound. The sponge should not be placed directly over major exposed blood vessels and organs. If vasculature or major organs are exposed, petroleum-impregnated gauze should be interposed between the vital structure and sponge. The system should not be used in nonenteric fistulae that are unexplored without knowing what may lie at the base of the fistula. In addition to these definitive contraindications, it is a relative contraindication using NPWT for chemotherapeutic extravasation injury and radiodermatitis because of lack of enough scientific preclinical data in using NPWT for these indications. ${ }^{1}$

Extravasation injury is defined as tissue damage caused by leakage of different kinds of intravenous medications to the interstitial space of a vein's surrounding tissue. The most common pharmacologic agents causing extravasation injury are osmotic active chemicals such as total parenteral nutrition, cationic solutions such as potassium $\left(\mathrm{K}^{+}\right)$, calcium $\left(\mathrm{Ca}^{++}\right)$and cytotoxic drugs. Among cytotoxic agents adriamycin (doxorubicin 
hydrochloride) is the chemotherapeutic causing the most serious extravasation injury. ${ }^{[14]}$

Chemotherapeutic extravasation wound differs from acute wounds and mimics chronic wound behaviour. Doxorubicin remains in the tissue for months, at which time it is extravasated. ${ }^{[15]}$ It retains its action on the neighbouring cells after it is released from necrotic cells. It may cause progressive ulceration and necrosis. ${ }^{[16]}$ Progressive ulceration may progress beneath tissues, including subcutaneous tissue, muscle, tendon, bone, and nerves. Histologically, these ulcers have an insufficient inflammatory response..$^{[17]}$

The prevention or early effective treatment of chemotherapeutics extravasation in the fragile cancer patients is of particular importance, not only because of the morbidity of surgical therapy of the extravasation induced injury in these immunocompromised patients with slow wound healing rates, but also because of the indolent insidious nature of the developing ulcer which tends to progress and erode the deeper structures as the time elapse. Although several conservative measures and surgical methods were described for the management of these injuries; unfortunately, once extravasation occurs, neither surgical nor supportive nonsurgical therapies are satisfactory, therefore, more effective methods need to be developed. ${ }^{[18]}$

There are only few sporadic reports of using NPWT in extravasation of toxic medications and venomous bites to aspirate toxic materials that remain in the wound environment after debridement. ${ }^{[1,19]}$ Efficacy of using NPWT in management of chemotherapeutic extravasation ulcer after the development of the ulcer, on the other hand, still needs to be evaluated.

\section{MATERIALS AND METHODS}

All the surgical procedures of the study were done after obtaining written approval from Hacettepe University Animal Care Ethical Review Committee.

\section{Experimental groups}

Experiment consisted of two groups:

1. NPWT therapy applied $(n=6)$ and

2. Conventional dressing $(n=6)$ groups.

\section{Surgical technique}

Twelve female albino New Zealand rabbits, weighing 3820-4070 g. were used in the experiment. Animals conditioned to the environment 10 days before the experiment and fed with standard rabbit diet.

VAC $^{\circledR} \quad$ (Vacuum Assisted Closure ${ }^{\mathrm{TM}}$ ) ATS $^{\circledR}$ (Advanced Therapy System ${ }^{\mathrm{TM}}$ ) device (KCI, San Antonio, Texas, USA) used for the topical negative pressure therapy.

All procedures on animals carried out under general anaesthesia. $1.5 \mathrm{ml} \% 10 \mathrm{Ketasol}^{\circledR}(100 \mathrm{mg} / \mathrm{ml}$ ketamine hydrochloride, $0.1 \mathrm{mg} / \mathrm{ml}$ benzetonyum chloride) (Richter Pharma Ag, Austria) and $0.5 \mathrm{ml} \% 2$ Alfazyne $^{\circledR}(20 \mathrm{mg} / \mathrm{ml}$ xylazine hydrochloride) (Alfasan International, Holland) cocktail was used for general anaesthesia. The backs of all animals were shaved from neck to the gluteal region. Lyophilised Adriblastina ${ }^{\circledR} 10 \mathrm{mg}$ (doxorubicin hydrochloride $10 \mathrm{mg}$ ) (Carlo Erba, Istanbul, Turkey) was dissolved in $5 \mathrm{ml}$ of sterile injection water, and $2 \mathrm{mg} / \mathrm{ml}$ concentration solution was prepared. $0.5 \mathrm{ml}$ of this solution is injected intradermally at 4 sites $3 \mathrm{~cm}$ apart from each other forming a square on the back of the animal. This procedure leads to the development of necrosis and eschar formation with an approximate diameter of $1 \mathrm{~cm}$ at each injection site [Figure 1a]. Then these areas are marked for debridement. Marked areas are excised down to panniclus carniosus [Figure 1b].

In the control group (conventional dressing group), the wounds were cleaned with saline, then polimisin ophtalmic pomade $^{\circledR}$ (Kocak Farma, Turkey) and Xeroform ${ }^{\circledR}$ (Tyco Healthcare Group, USA) was applied topically for moist dressing. Dressings were changed daily. In NPWT therapy group, the wounds were cleaned with saline as in the control group. Then standard NPWT application with NPWT granufoam dressing was applied and draped with sterile airtight self-adhesive tape. NPWT dressing,

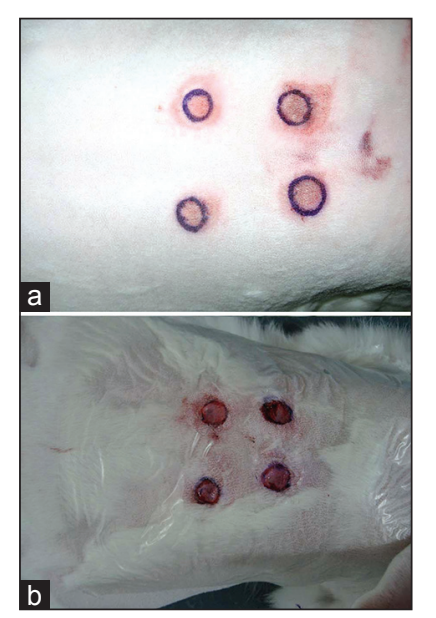

Figure 1: Macroscopic appearance of the wounds (a) After development of the necrosis, (b) After debridement of the necrotic area 
which was changed daily was protected with a technique described in the literature and changed daily. ${ }^{[20]}$

\section{Histological evaluations}

On $3^{\text {rd }}, 7^{\text {th }}$ and $14^{\text {th }}$ days, the wound areas were marked on transparent paper and measured. One of the four wounds on the animals were excised and halved. One piece was put into $10 \%$ buffered formaldehyde solution for light microscopic examination, while the other half was preserved in liquid nitrogen for immunohistochemical study. At the end of the experiment, all animals were sacrificed by carbon dioxide inhalation method.

Wound specimens were fixated in $10 \%$ buffered formaldehyde solution for $72 \mathrm{~h}$. After fixation wound specimens were processed according to routine light microscopic technique and embedded in paraffin. $5 \mu \mathrm{m}$ thick serial sections were stained with haematoxylin - eosin and Masson's trichrome stains. All the samples were examined and photographed with Leica DMR-RCM microscope (Reflection Contrast Microscope, Wetzlar-Germany). Neovascularization was demonstrated with CD31 monoclonal antibodies and DAKO envision kit for immunohistochemical study.

For the immunohistochemical evaluation of blood vessels CD31 monoclonal antibody was used. All the blood vessels immunoreactive with CD31 in the wound area were counted with Leica DMR-RCM microscope at $\times 40$ magnification by two histologists independently.

Histological findingswere evaluated asneovascularisation, epithelisation, granulation tissue formation and inflammatory cell presence according to modified Abramov et al.'s scoring system ${ }^{[21]}$ [Table 1].

\section{Statistics}

The wound areas and neovascularization, epithelisation, granulation tissue formation and inflammatory cell count

Table 1: Histologic scoring system used for evaluation of the wounds*

\begin{tabular}{|c|c|c|c|c|}
\hline \multirow[t]{2}{*}{ Variable } & \multicolumn{4}{|c|}{ Score } \\
\hline & 0 & 1 & 2 & 3 \\
\hline Epithelization & None & Partial & $\begin{array}{c}\text { Complete, } \\
\text { immature/thin }\end{array}$ & $\begin{array}{l}\text { Complete, } \\
\text { mature }\end{array}$ \\
\hline Neovascularization & None & $<10$ vessels & $10-20$ vessels & $>20$ vessels \\
\hline $\begin{array}{l}\text { Granulation tissue } \\
\text { formation }\end{array}$ & None & Few & Moderate & Many \\
\hline $\begin{array}{l}\text { Inflammatory } \\
\text { cell count }\end{array}$ & None & Few & Moderate & Many \\
\hline
\end{tabular}

scores that were obtained from histological study were all analysed statistically both within and between the groups at $3^{\text {rd }}, 7^{\text {th }}$ and $14^{\text {th }}$ days. For statistical analysis, SPSS 11.5 for Windows was used. Two-way ANOVA test was used to compare wound areas between groups. Willcoxon sign test with Bonferroni correction was used to compare histological scores between groups. Chi-square test with Bonferroni correction was used to compare histological scores within the group between the days.

\section{RESULTS}

\section{Macroscopic findings}

On the $3^{\text {rd }}$ day after debridement of the wounds; the wound edges of NPWT group were more regular, and tiny granulation tissue formation was observed compared to conventional dressing group, in which the wound edges were more irregular, and the wound was covered with fibrin tissue. On the $7^{\text {th }}$ day; wound areas in NPWT group were smaller than that of conventional dressing group. The granulation tissue formation was just started in conventional dressing group. On the $14^{\text {th }}$ day; the wounds in conventional dressing group were more crusty and dry compared to NPWT group [Figure 2]. All wounds were $78 \mathrm{~mm}^{2}$ right after the debridement (i.e., the wound with a diameter of $1 \mathrm{~cm}$ ). At the $14^{\text {th }}$ day mean wound area in NPWT group was $46.8 \mathrm{~mm}^{2}$ while it was $59.1 \mathrm{~mm}^{2}$ in conventional dressing group. Wound

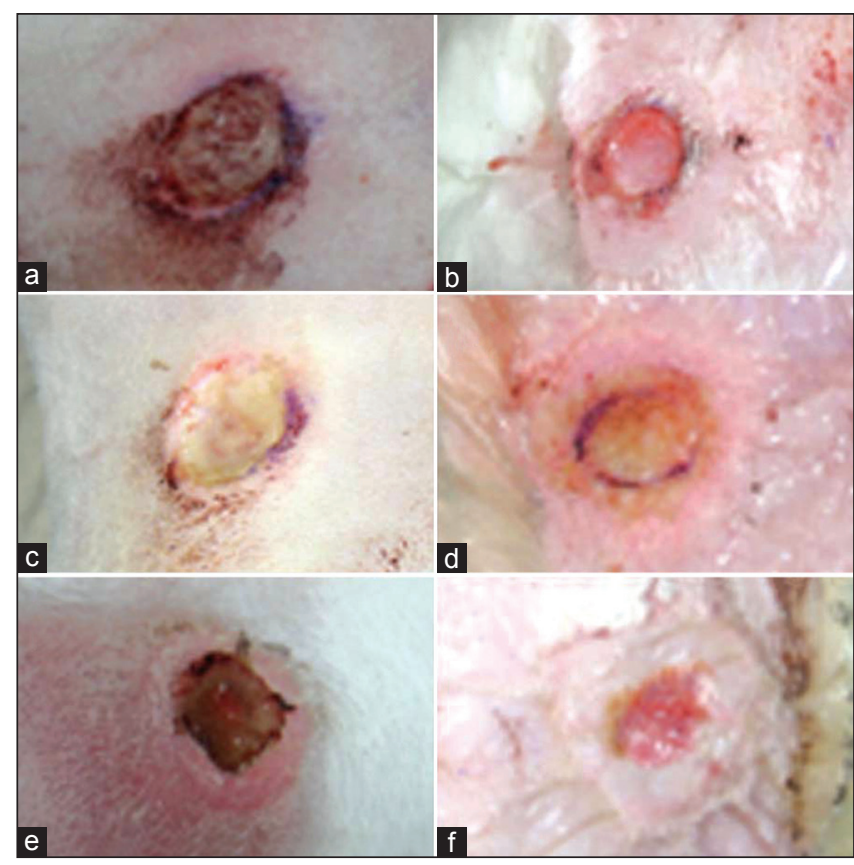

Figure 2: Macroscopic appearance of the wounds (a) Control group at $3^{\text {rd }}$ day, (b) Negative pressure wound therapy (NPWT) group at $3^{\text {rd }}$ day, (c) Control group at $7^{\text {th }}$ day, (d) NPWT group at $7^{\text {th }}$ day, (e) Control group at $14^{\text {th }}$ day, (f) NPWT group at $14^{\text {th }}$ day 
areas were significantly smaller in NPWT group compared to conventional dressing group $(P<0.05)$ and decrease in size of wound areas were statistically significant between days within the groups $(P<0.05)$ [Figure 3].

\section{Microscopic findings \\ Third day}

All samples in NPWT group had a thin layer of granulation tissue. Collagen fibres were thicker at the surface and thinner at the deeper levels. Many infiltrative cells were observed in the wound in between the necrotic muscle fibres. Similar granulation tissue was observed in all samples of the dressings group. Similar to NPWT group collagen fibres were thicker at the surface of the wound but at deeper levels they were thin, short and dispersed from each other due to oedema [Figure $4 \mathrm{a}$ and $\mathrm{b}$ ].

\section{Seventh-day}

Epithelisation did not begin in any of the specimens in NPWT group on $7^{\text {th }}$ day. A thick layer of granulation was seen at the centre of the wound. Parallely arranged thick collagen fibres were observed at the periphery of the wound and beneath the muscle layer. Infiltrative cells were present in between the necrotic muscle bundles. Granulation tissue was thick in dressing group, but collagen fibres were thin and irregularly oriented. Vascularization was better, but collagen fibres were scattered irregularly in dressing group when compared with the NPWT group [Figure $4 \mathrm{c}$ and $\mathrm{d}$ ].

\section{Fourteenth day}

No epithelisation was observed in NPWT group but in dressing group epithelisation that had begun in $7^{\text {th }}$ day was progressed towards the centre. The orientation of collagen fibres in NPWT group resembled normal dermis but in dressing group it was more like that of scar tissue [Figure $4 \mathrm{e}$ and $\mathrm{f}$ ].

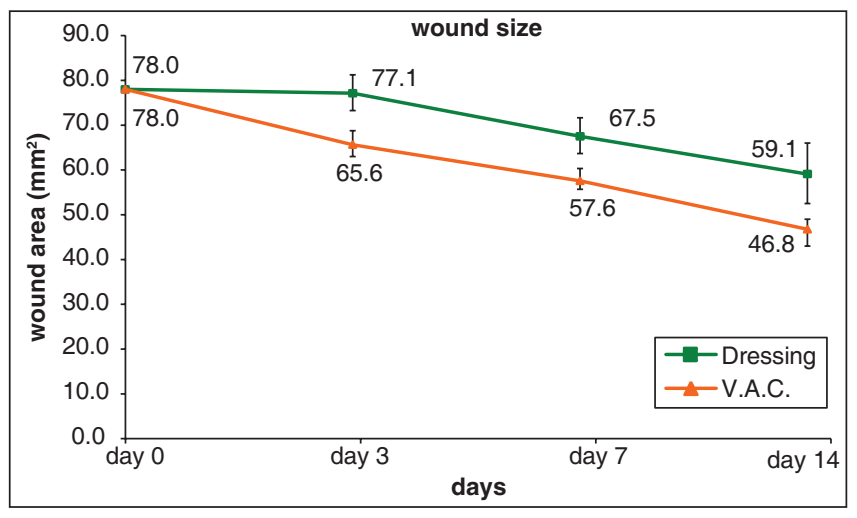

Figure 3: Wound size according to the postoperative days

\section{Histological scoring}

Epithelisation scoring increased after $3^{\text {rd }}$ day in dressing group but was 0 in NPWT group. This increase in epithelisation scores in dressing group is statistically significant $(P<0.05)$. Neovascularisation scores are same for both dressing and NPWT group on the $3^{\text {rd }}$ day but slightly more on the $7^{\text {th }}$ and $14^{\text {th }}$ days in dressing group which is not found to be statistically significant $(P>0.05)$. Granulation tissue scores were higher in the NPWT group than in the dressing group slight decrease of the score seen in $14^{\text {th }}$ day in NPWT group, but the granulation score changes between the days within the groups and between the groups were not statistically significant $(P>0.05)$ inflammatory cell scores decreased in days after the $3^{\text {rd }}$ day in both groups which were statistically significant $(P<0.05)$, but the difference between the groups regarding inflammatory cell scores was not significant $(P>0.05)$.

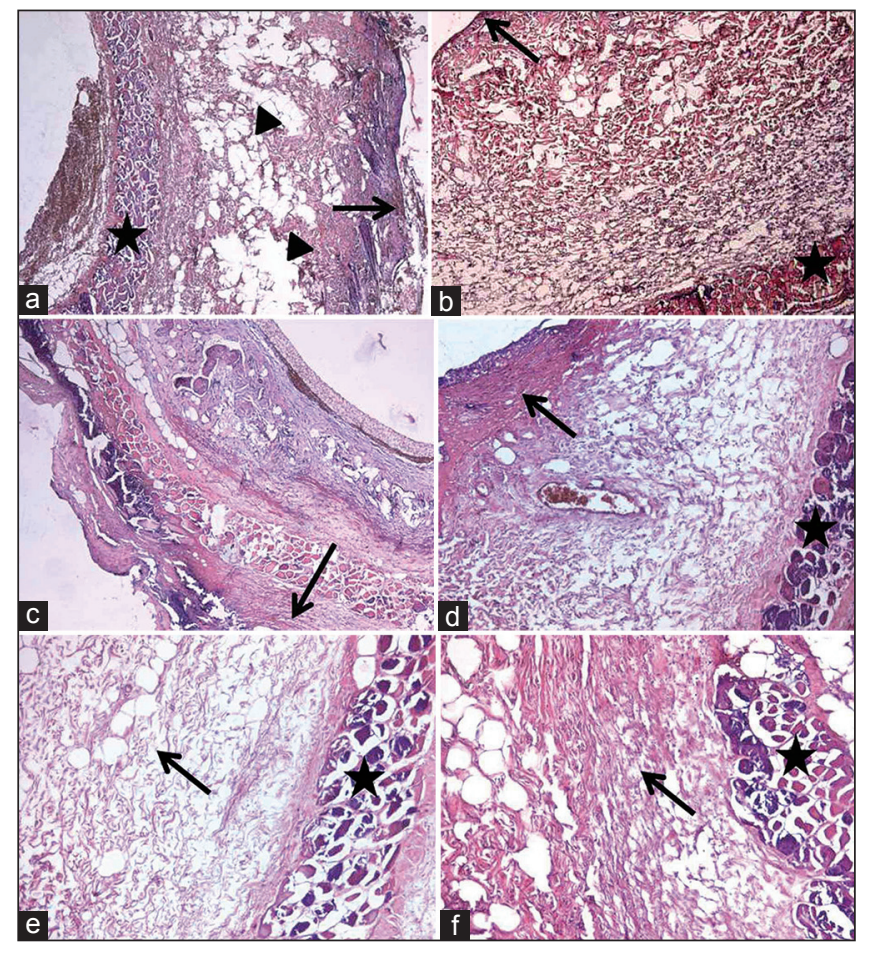

Figure 4: (a) Microscopic pictures of the groups: Negative pressure wound therapy (NPWT) group at $3^{\text {rd }}$ day; a thin layer of granulation tissue (arrow) above edematous areas (arrow head) between the thick collagen fibers and deeply located necrotic muscle fibers (star). (b) Microscopic pictures of the groups: Dressing group at $3^{\text {rd }}$ day; granulation tissue is similar to NPWT group but with thin collagen fibers underneath (arrow: Granulation tissue, star: Necrotic muscle fibers). (c) Microscopic pictures of the groups: Dressing group at $3^{\text {rd }}$ day; granulation tissue is similar to NPWT group but with thin collagen fibers underneath (arrow: Granulation tissue, star: Necrotic muscle fibers). (d) Microscopic pictures of the groups: Dressing group at $7^{\text {th }}$ day; thick granulation tissue composed of irregularly arranged thin collagen fibers (arrow) above the necrotic muscle fibers (star). (e) Microscopic pictures of the groups: NPWT group at $14^{\text {th }}$ day; edematous connective tissue composed of collagen fibers resembling dermis (arrow) and necrotic muscle fibers (star). (f) Microscopic pictures of the groups: Dressing group at $14^{\text {th }}$ day; collagen fibers oriented as scar tissue (arrow) above necrotic muscle fibers (star) 


\section{DISCUSSION}

Extravasation injury, caused by leakage of a pharmacologic agent to surrounding tissue may result in severe tissue necrosis and damage, especially in children and elderly cancer patients, who have already diminished wound healing capacity. Despite institutional efforts and guidelines to prevent extravasation, it is not possible to completely eradicate this problem. Therefore, any interventions in the treatment of chemotherapeutics' extravasation in the fragile cancer patients aiming reducing patients' suffer, hospital stay and the medical expenses are worth to consider.

Over the last 20 years, NPWT has been commonly used for treatment of a wide variety of complex wounds and has dramatically changed the outcomes. The beneficial effects were thought to come from mainly; removal of excess interstitial fluid that contains inflammatory cytokines, collagenases and elastases and also relieving the microcirculation, delivering mechanical stress to the wound, providing a relative moist environment, stimulating angiogenesis and reducing bacterial count.

Although NPWT system is originally designed for chronic wound management and successfully used for venous ulcer, diabetic foot wound, bed sores, infected sternal wound, large tissue defects of both extremities and torso due to trauma, oncologic surgery etc.; there are only a few reports of use of NPWT therapy for extravasation ulcers. ${ }^{[22-25]}$ von Gossler et al. showed that negative pressure therapy decreased the necrosis formation in extravasation injured tissues in an experiment on pigs. ${ }^{[19]}$ There has been a clinical report of the use of the NPWT to successfully treat a toxic beetle bite. ${ }^{[26]}$

Goon and Dalal applied NPWT successfully for an extensive ulcer on the arm of a patient who had had doxorubicin extravasation ulcer. ${ }^{[27]}$ In both of these reports, the aim of using NPWT was to aspirate toxic materials that remain in the wound environment after debridement in order to prevent the development of progressive tissue necrosis. To the best of our knowledge, this is the first study investigating the efficacy of NPWT on established necrotic wounds, resulted from chemotherapeutic extravasation.

Although the microscopic and the macroscopic findings of this study do not seem to be complementary to each other, they highlight the effect of NPWT in this particular clinical situation. There is no significant difference in terms of inflammatory cell count, neovascularization, granulation tissue formation between the groups and even the conventional treatment group has better epithelisation parameters when compared with the NPWT group in terms of microscopic findings. Open wound area, on the other hand, apparently diminished better in the NPWT applied group, which demonstrates the beneficial effect of NPWT due to the centripetal mechanical stress to the wound. Although there are various reports claiming that NPWT enhances wound contraction and decreases wound area via mechanical stress, there is no information regarding the effect of NPWT on loose versus tight skin/tissue, in the literature. Consequently this factor was not considered in our study. Our experimental findings suggested that mechanical properties have greater influence on clinical efficacy of NPWT. Microscopically, collagen fibres in NPWT group wounds were more organized, thicker and more like normal dermis but in dressing group they were thinner and dispersed and more of like a scar tissue.

Before proceeding to use of NPWT in human extravasation injuries, demonstration of the difference of scar maturation of the extravasation ulcers between the NPWT applied group and conventional dressing group in larger animals, such as pigs may be significant. In addition to the shortterm advantage of NPWT on wound closure, demonstration of the beneficial effect of the NPWT on long term scar maturation will remain an area of interest in future.

\section{REFERENCES}

1. Marks MW, Argenta LC, DeFranzo AJ. Principles and aplications of vacuum-assisted closure (VAC). In: Weinzweig J, editor. Plastic Surgery Secrets. $2^{\text {nd }}$ ed. Philadelphia: Mosby Inc.; 2010. p. 38-44.

2. Orgill DP, Bayer LR. Update on negative-pressure wound therapy. Plast Reconstr Surg 2011;127:105S-115.

3. Argenta LC, Morykwas MJ, Marks MW, DeFranzo AJ, Molnar JA, David LR. Vacuum-assisted closure: State of clinic art. Plast Reconstr Surg 2006;117:127S-42.

4. Morykwas MJ, Simpson J, Punger K, Argenta A, Kremers L, Argenta J. Vacuum-assisted closure: State of basic research and physiologic foundation. Plast Reconstr Surg 2006;117:121S-6.

5. Morykwas MJ, Argenta LC, Shelton-Brown El, McGuirt W. Vacuum-assisted closure: A new method for wound control and treatment: Animal studies and basic foundation. Ann Plast Surg 1997;38:553-62.

6. Chen SZ, Li J, Li XY, Xu LS. Effects of vacuum-assisted closure on wound microcirculation: An experimental study. Asian J Surg 2005;28:211-7.

7. Menke NB, Ward KR, Witten TM, Bonchev DG, Diegelmann RF. Impaired wound healing. Clin Dermatol 2007;25:19-25.

8. Ladwig GP, Robson MC, Liu R, Kuhn MA, Muir DF, Schultz GS. Ratios of activated matrix metalloproteinase- 9 to tissue inhibitor of matrix metalloproteinase- 1 in wound fluids are inversely correlated with healing of pressure ulcers. Wound Repair Regen 2002;10:26-37. 
9. Kirsner RS, Katz MH, Eaglstein $\mathrm{WH}$, Falanga $\mathrm{V}$. The biology of wound fluid. Wounds 1993;5:122-8.

10. Raffetto JD, Mendez MV, Marien BJ, Byers HR, Phillips TJ, Park HY, et al. Changes in cellular motility and cytoskeletal actin in fibroblasts from patients with chronic venous insufficiency and in neonatal fibroblasts in the presence of chronic wound fluid. $J$ Vasc Surg 2001;33:1233-41.

11. Greene AK, Puder M, Roy R, Arsenault D, Kwei S, Moses MA, et al. Microdeformational wound therapy: Effects on angiogenesis and matrix metalloproteinases in chronic wounds of 3 debilitated patients. Ann Plast Surg 2006;56:418-22.

12. Chen KD, Li YS, Kim M, Li S, Yuan S, Chien S, et al. Mechanotransduction in response to shear stress. Roles of receptor tyrosine kinases, integrins, and Shc. J Biol Chem 1999; 274:18393-400.

13. Chen SZ, Cao DY, Li JQ, Tang SY. Effect of vacuum-assisted closure on the expression of proto-oncogenes and its significance during wound healing. Zhonghua Zheng Xing Wai Ke Za Zhi 2005;21:197-200.

14. Konas E, Canter HI, Korkusuz P, Demir D, Oner F, Mavili ME. A new concept in the treatment of extravasation injury: Controlled drug delivery systems. J BUON 2010;15:592-600.

15. Heckler FR. Current thoughts on extravasation injuries. Clin Plast Surg 1989;16:557-63.

16. Disa JJ, Chang RR, Mucci SJ, Goldberg NH. Prevention of adriamycin-induced full-thickness skin loss using hyaluronidase infiltration. Plast Reconstr Surg 1998;101:370-4.

17. Luedke DW, Kennedy PS, Rietschel RL. Histopathogenesis of skin and subcutaneous injury induced by adriamycin. Plast Reconstr Surg 1979;63:463-5.

18. Vargel I, Canter HI, Erdem A, Altundag MK. Results of GM-CSF treatment in chemotherapeutic extravasation ulcers. J BUON 2010;15:608-9.

19. Morykwas MJ, Kennedy A, Argenta JP, Argenta LC. Use of subatmospheric pressure to prevent doxorubicin extravasation ulcers in a swine model. J Surg Oncol 1999;72:14-7.

20. Isci E, Canter HI, Kecik A. A new custom made dressing and wound protective for rabbits. Eur J Plast Surg 2007;30:45-6.

21. Abramov Y, Golden B, Sullivan M, Botros SM, Miller JJ, Alshahrour $\mathrm{A}$, et al. Histologic characterization of vaginal vs. abdominal surgical wound healing in a rabbit model. Wound Repair Regen 2007;15:80-6.

22. Agarwal JP, Ogilvie M, Wu LC, Lohman RF, Gottlieb LJ, Franczyk M, et al. Vacuum-assisted closure for sternal wounds: A first-line therapeutic management approach. Plast Reconstr Surg 2005;116:1035-40.

23. Tang AT, Ohri SK, Haw MP. Novel application of vacuum assisted closure technique to the treatment of sternotomy wound infection. Eur J Cardiothorac Surg 2000;17:482-4.

24. O'Connor J, Kells A, Henry S, Scalea T. Vacuum-assisted closure for the treatment of complex chest wounds. Ann Thorac Surg 2005;79:1196-200.

25. Orgill DP, Bayer LR. Advancing the treatment options of chest wounds with negative pressure wound therapy. Ostomy Wound Manage 2005;51:39S-43.

26. von Gossler CM, Horch RE. Rapid aggressive soft-tissue necrosis after beetle bite can be treated by radical necrectomy and vacuum suction-assisted closure. J Cutan Med Surg 2000;4:219-22.

27. Goon PK, Dalal M. Limb-threatening extravasation injury: Topical negative pressure and limb salvage. Plast Reconstr Surg 2006;117:1064-5.

How to cite this article: Isci E, Canter HI, Dadaci M, Atilla P, Cakar AN, Kecik A. The efficacy of negative pressure wound therapy on chemotherapeutic extravasation ulcers: An experimental study. Indian J Plast Surg 2014;47:394-400.

Source of Support: Upported by Hacettepe University Research Foundation, Conflict of Interest: None declared. 